Case Report

\title{
Asymptomatic immune thrombocytopenia in immediate post surgery following fresh frozen plasma transfusion
}

\author{
Ankita Singh, Mohammed Fawaz, Yashwant Singh Rathore*, Sunil Chumber
}

Department of Surgical Disciplines, All India Institute of Medical Sciences, Delhi, India

Received: 20 September 2021

Accepted: 13 October 2021

\section{*Correspondence:}

Dr. Yashwant Singh Rathore,

E-mail: dryashvant.r@gmail.com

Copyright: ( $\subseteq$ the author(s), publisher and licensee Medip Academy. This is an open-access article distributed under the terms of the Creative Commons Attribution Non-Commercial License, which permits unrestricted non-commercial use, distribution, and reproduction in any medium, provided the original work is properly cited.

\begin{abstract}
Occurrence of thrombocytopenia in immediate post operative period is less frequently encountered, and identifying the cause(s) is also challenging. Because multiple interventions in the form of fluid administrations, blood products transfusion, use of drugs (heparin) and increased risk of infection and organ dysfunction in post operative period can all cause thrombocytopenia. Fresh frozen plasma transfusion (FFP) transfusion is an uncommon cause of drastic thrombocytopenia, with only 14 such reported cases in the literature. And this complication is most frequently witnessed in perioperative period, 11 out of 14 of all reported cases. It is explained by transfusion of plasma containing antibodies against platelets, which develop as a consequence of plasma donors being exposed to varied platelet antigen via previous blood transfusion or during pregnancy. Here we are presenting a case of a young male who was transfused with FFP in post-operative period which led to a drastic fall in platelet count without any bleeding manifestations, which was a diagnosis of exclusion and managed with suspension of FFP transfusion
\end{abstract}

Keywords: Immune thrombocytopenia, FFP induced thrombocytopenia, Plasma transfusion induced thrombocytopenia, Post surgery thrombocytopenia

\section{INTRODUCTION}

Causes of thrombocytopenia occurring in immediate post operative period are difficult to recognize, due to multiple interventions in both intraoperative and postoperative period, altered physiology and risk of infections and organ dysfunctions. ${ }^{1}$ All of which are known to cause fall in platelet counts. One such intervention is blood and blood product transfusion whenever indicated, carries some risk of transfusion reaction. Thrombocytopenia occurring as a complication of fresh frozen plasma (FFP) transfusion is quite uncommon. There are 14 documented cases of thrombocytopenia related to transfusion of FFP, most of which occurred in perioperative period i.e. 11 out of 14 cases. $^{2-5}$
The possible mechanism is immune mediated destruction of platelets by passive transfer of antiplatelet antibodies from blood donors. Diagnosis is made by demonstration of antiplatelet antibodies in donor's blood with presence of respective antigen in recipient or diagnosis of exclusion. Treatment involves immediate suspension of FFP transfusion and subsequent symptomatic therapy, including administration of IVIG, steroids and platelet transfusion.

Here we are presenting a case of 26 years male who developed a drastic fall in platelet counts following 3 units of FFP transfusion given post operatively. Which subsequently improved to normal in 1 week of stopping FFP transfusion. Diagnosis of exclusion of FFP induced thrombocytopenia was made. 


\section{CASE REPORT}

A 26 years old male, presented to emergency department with features suggestive of subacute intestinal obstruction with incisional hernia. There was history of similar episodes in the past for last 2 years, which were managed conservatively. Emergency resuscitation and expectant management lead to resolution of symptoms. However due to recurrence of symptoms, imaging in form of CECT abdomen was done which was suggestive of multiple long segment strictures in the distal ileum. After stabilization patient was planned for laparotomy, he underwent exploratory laparotomy in view of benign stricture right limited hemicolectomy, side to side ileoascending anastomosis and primary hernia repair was performed. In view of large intraoperative dissection, ooze and resection and anastomosis, post-operative FFP transfusion was planned. Two units FFP were transfused on post surgery day 1 . On second day following third
FFP transfusion drastic fall in platelet count, from 1.80 lakh to 60,000 was documented. Thus 4th FFP transfusion was withheld. There was no evidence of bleeding from any site or any other symptoms of transfusion reaction. Post-operative sepsis was ruled out as cause of thrombocytopenia, as total leucocyte count, procalcitonin and lactate levels were within normal limits. Patient was not on any drug that would cause sudden fall in platelet counts. Except intravenous cefoperazone, which is again an uncommon cause of thrombocytopenia and literature review suggests that it is not caused by single dose. ${ }^{6}$ The peripheral smear and bone marrow aspirate could not be done for further work up because as soon as FFP transfusion was stopped, his platelet counts started improving (Table 1). Subsequently patient was discharged without any sequalae of thrombocytopenia and recovered platelet count after 1 week of stopping FFP transfusion.

Table 1. Patient platelets counts during the post-operative course.

\begin{tabular}{|llllll|}
\hline Parameter & Pre-surgery & $\begin{array}{l}\text { Post-operative } \\
\text { day } 1 \\
\text { 2 units FFP }\end{array}$ & $\begin{array}{l}\text { Post-operative } \\
\text { day } 2 \\
2^{\text {nd }} \\
\text { withit FFP }\end{array}$ & $\begin{array}{l}\text { Post-operative } \\
\text { day 5 }\end{array}$ & $\begin{array}{l}\text { Post-operative day } 7 \\
\text { Post-transfusion day } \\
7\end{array}$ \\
\hline Platelet count & $1,81,000$ & & 60,000 & $1,17,000$ & $1,40,000$ \\
\hline
\end{tabular}

\section{DISCUSSION}

Thrombocytopenia has been defined as when blood platelets counts fall below 1 lac/cumm. There are various causes have explained in the literature, but in immediate post operative period, sudden thrombocytopenia is uncommon and identifying the cause of post-operative thrombocytopenia is very challenging and important to prevent adverse outcomes. As thrombocytopenia may be caused by post-operative infections, sepsis or numerous interventions in the form of intravenous fluid administration, whole blood transfusion (hemodilutional thrombocytopenia), and even medications (e.g. heparin, rarely cefoperazone and others). ${ }^{1,6}$ FFP transfusion is seldom documented cause of thrombocytopenia. So far only 14 such cases, including 11 cases during peri operative period have been documented. ${ }^{2-5,7}$ Which was probably the cause of thrombocytopenia in our patient on post operative day 2 , as all the above causes were excluded. It is confirmed by demonstration of antiplatelet antibody in donor FFP with presence of respective antigen in recipient, or is a diagnosis of exclusion..$^{2-5,7-9}$

The possible mechanism of development of these antiplatelet antibodies is exposure of platelet antigennegative donor to a common platelet antigen, either through prior transfusion or pregnancy and often pregnancy losses. And transfusion of such plasma containing antibodies from sensitized donor into an antigen positive recipient binds to respective antigen on recipient's platelets. This can lead to drastic fall in platelets leading to bleeding manifestations, acute transfusion reaction or even death.

Alloantibodies detected in donor FFP that led to immune thrombocytopenia were most frequently anti PI(A1) also known as anti HPA-1a. ${ }^{2,4,7-9}$ And 1 case each due to antiCD36(Nak) isoantibody3, anti HPA-1a/1b antibody2 and anti HPA 5 b antibody 5 .

The fall in platelet count has been seen as early as within 1 hour to maximum 2 days of FFP transfusion. ${ }^{2,10}$ Anti platelet antibodies found in donor plasma were mostly detected in all cases, along the respective antigen in recepient. And cross match done between the patient's platelets and the FFP was positive. $^{3}$

Immune thrombocytopenia is a potentially dangerous complication of FFP transfusion. This condition has been reported to be accompanied by symptoms of acute transfusion reaction (seen in $30 \%$ reported cases) in the form of tightness in chest, nausea, hypotension, apart from thrombocytopenic bleeding found in approximately $75 \%$ of recipients and even possible death. Or rarely be asymptomatic with incidental drastic fall in platelet counts post transfusion, as was the witnessed in our case.

Review of literature has suggested all FFP donors were females with history of pregnancy and often with pregnancy losses except one case where plasma donor was male. ${ }^{7,9}$ Thus implicating sensitization of donors with antigen positive fetus as probable explanation for development of antiplatelet antibodies. Thus male donor 
plasma transfusions can lead to decrease in such cases. And so is detailed donor history to rule out potential female donors if they have been pregnant in last 6 weeks or are currently pregnant; as included in FDA approved Donor History Questionnaire. With a drawback that it does not ask regarding past pregnancies. ${ }^{7}$

Management is immediately stopping FFP transfusion, at clinical suspicion. As this was done in our case and symptomatic management of patients with bleeding or acute transfusion reaction, which also included platelet transfusion and administration of IVIG and steroids.

Recovery of platelets to normal counts was seen between 1-14 days, and most frequently a week of stopping FFP transfusion. $^{2-5,7-9}$ It took almost a week for our patient's thrombocytopenia to recover after withholding further FFP transfusions and without any other intervention.

\section{CONCLUSION}

The possibility of passive infusion of anti platelet antibodies while transfusing FFP should be considered in unexplained thrombocytopenia post operatively, which may or may not be preceded by acute transfusion reactions. Immune thrombocytopenia can also present without transfusion reaction symptoms, routine blood investigations may help to detect this thrombocytopenia. Withholding FFP transfusion is sufficient in case of asymptomatic immune thrombocytopenia, but in case of symptomatic thrombocytopenia along with withholding FFP transfusion, supportive management in the form of antihistaminics, antipyretics, platelet transfusion, IVIG, steroids etc. may also be needed. Careful exclusion of potential causes of thrombocytopenia in post-operative cases is needed, before making final diagnosis. Conservative transfusion practices and more targeted donor screening may prevent similar events. The investigation should be undertaken to rule out passive transfer of antiplatelet antibodies, to document such cases. Resultantly the implicated donors should be actively deferred for future donations.

Funding: No funding sources

Conflict of interest: None declared

Ethical approval: Not required

\section{REFERENCES}

1. Skeith L, Kreuziger LB, Crowther MA, Warkentin TE. A practical approach to evaluating postoperative thrombocytopenia. Blood Adv. 2020;4(4):776-83.

2. Pavenski K, Webert KE, Goldman M. Consequences of transfusion of platelet antibody: a case report and literature review. Transfusion (Paris). 2008;48(9):1981-9.

3. Morishita K, Wakamoto S, Miyazaki T, Sato S, Fujihara M, Kaneko S, et al. Life-threatening adverse reaction followed by thrombocytopenia after passive transfusion of fresh frozen plasma containing anti-CD36 (Naka) isoantibody. Transfusion (Paris). 2005;45(5):803-6.

4. Nijjar TS, Bonacosa IA, Israels LG. Severe acute thrombocytopenia following infusion of plasma containing anti P1A1. Am J Hematol. 1987;25(2):219-21.

5. Warkentin TE, Smith JW, Hayward CPM, Ali AM, Kelton JG. Thrombocytopenia caused by Passive Transfusion of Anti-Glycoprotein Ia/IIa alloantibody (anti-HPA-5b). Blood. 1992;79(9):2480-4.

6. Avinash A, Kunder SK, Magazine BC, Bairy KL, Adiga S. Cefoperazone: A Rare Cause of Thrombocytopenia. Journal of Applied Pharmaceutical Science. 2016;6(12):190-1.

7. Collins CL, Scott JP, Panepinto JA, Punzalan RC. Severe Thrombocytopenia in a Child Secondary to Passive Platelet Antibody Transfer from a Plasma Transfusion. J Pediatr Hematol/Oncol. 2013;35(5):e226-8.

8. Brunner-Bolliger S, Kiefel V, Horber FF, Nydegger UE, Berchtold P. Antibody studies in a patient with acute thrombocytopenia following infusion of plasma containing anti-PI(A1). Am J Hematol. 1997;56:119-21.

9. Drakaki A, Blanchard E. Fresh frozen plasma induced thrombocytopenia. Case Reports in Clinical Medicine. 2013;2(2):123-5.

10. Solenthaler M, Krauss JK, Boehlen F, Koller R, Hug M, Lammle B. Fatal fresh frozen plasma infusion containing HPA-1a alloantibodies. $\mathrm{Br} \mathrm{J}$ Haematol 1999;106:252-62.

Cite this article as: Singh A, Fawaz M, Rathore YS, Chumber S. Asymptomatic immune thrombocytopenia in immediate post surgery following fresh frozen plasma transfusion. Int Surg J 2021;8:3472-4. 